\title{
EL RETORNO A LO ADMINISTRATIVO: COMENTARIO A LA SENTENCIA ROL No 1079-2014 DE LA CORTE
SUPREMA, "FISCO DE CHILE CON DÖRR ZEGERS
Y OTROS" ("CHISPAS II")*
}

The RetUrn to the Administrative: Commentary on

THE JUDGMENT No 1079-2014 OF THE CHILEAN

Supreme Court, "Chilean Treasury with Dörr Zegers AND OTHERs" (“ChISPAS II")

FRANCISCO ZÚNiga URBINA* Universidad de Chile fzuniga@zdcabogados.cl

Es usual encontrar en nuestro ordenamiento jurídico normas que entregan facultades sancionadoras a órganos administrativos. Ello ha dado lugar a hablar de la "potestad sancionadora de la Administración" y del Derecho Administrativo Sancionador, el que podemos definir, siguiendo al profesor Bermúdez, como "el poder jurídico con que cuenta la Administración del Estado, de carácter permanente, expresamente atribuido por la ley, en virtud del cual se le habilita para perseguir al sujeto imputado de aquellas conductas activas u omisivas, que se estima son constitutivas de infracción administrativa e imponerle una retribución negativa o sanción por las mismas"1.

En nuestro ordenamiento estamos ya acostumbrados a la existencia de estas sanciones administrativas. Sin perjuicio de ello, un sector de la doctrina administrativista tradicional chilena, liderada por el profesor Eduardo Soto Kloss, en una orientación antiestatalista y no pacífica, sostuvo que esta potestad es contraria a la Constitución, toda vez que para que exista sanción, debe haber previamente

\footnotetext{
* Trabajo recibido el 6 de mayo de 2015 y aprobado el 13 de mayo de 2015.

** Profesor Titular de Derecho Constitucional, Departamento de Derecho Público, Universidad de Chile. Para la elaboración del comentario contamos con la colaboración del profesor Roberto Cárcamo Tapia.

1 Bermúdez (2010), p. 178.
} 
un juicio, y por ende un juez, un tercero imparcial, lo que evidentemente no existe cuando es la Administración la que sanciona lo que ella misma estima es una infracción ${ }^{2}$.

Superada esta tesis por el avance del derecho positivo así como de la jurisprudencia, se ha asentado la constitucionalidad de la potestad sancionadora de la Administración del Estado. Sin embargo, buscando dar garantías a los administrados ante el ejercicio de las manifestaciones de esta potestad, la doctrina y la jurisprudencia han echado mano, como se verá a continuación, a los principios y normas propios del Derecho Penal, en un inicio de forma más rígida, luego con cierta moderación; lo que se observa en la apelación a los "matices" entre el derecho punitivo penal y administrativo que hace la jurisprudencia del Tribunal Constitucional.

En tal contexto, la reciente sentencia de la Tercera Sala de la Corte Suprema en los autos rol No 1079-2014, caratulados "Fisco de Chile con Dörr Zegers y otros", implica una valiosa novedad dentro de nuestra jurisprudencia, al razonar ya "no sólo" desde los principios y normas del Derecho Penal, sino incluyendo en su razonamiento los principios, normas y la lógica del Derecho Administrativo. A continuación veremos en qué consiste la novedad y por qué, de continuar la jurisprudencia en esa línea, que por lo demás nos parece la correcta, esta sentencia puede cobrar capital importancia en nuestro ordenamiento.

\section{Antecedentes: El “Caso Chispas" y la muerte de Luis Fernando MackenNa}

Como se recuerda aún en Chile, el llamado "Caso Chispas" fue un escándalo bursátil y político ocurrido en 1997, originado por la compra de acciones de la empresa chilena Enersis por parte de Endesa España. Como es recordado, Enersis era dirigida por el ex funcionario del régimen autoritario José Yuraszeck como presidente, y por Marcos Zylberberg, Luis Fernando Mackenna, Marcelo Brito, Arsenio Molina y Eduardo Gardella. Este grupo de empresarios logró obtener un desmedido precio en desmedro de la mayor parte de los accionistas de la empresa, al negociar de forma aparte el precio del paquete controlador de la sociedad, por lo que fueron multados por la Superintendencia de Valores y Seguros por el ilícito de negociación incompatible por cerca de 75 millones de dólares. Luego, el 7 de

2 Soto (2010), pp. 429-435. 
julio de 2005 la Corte Suprema ratificó las multas, a propósito de un reclamo de ilegalidad. Sin embargo, con anterioridad, el $1^{\circ}$ de abril del mismo año, Luis Fernando Mackenna falleció.

En octubre de 2008, el Consejo de Defensa del Estado inició una demanda de cobro de pesos contra la sucesión del señor Mackenna, ante el $16^{\circ}$ Juzgado Civil de Santiago. Por sentencia de 30 de diciembre de 2011, dicho Juzgado rechazó la demanda fiscal. Impugnada esta sentencia mediante recurso de casación en la forma y de apelación, la Corte de Apelaciones de Santiago confirmó la sentencia de primera instancia mediante sentencia de segundo grado de fecha 19 de noviembre de 2013. Recurrida esta última de casación en el fondo, fue recientemente casada por la Tercera Sala de la Corte Suprema con fecha 30 de octubre de 2014, en fallo dividido, dictándose la correspondiente sentencia de reemplazo, la cual acogió la demanda fiscal, por alrededor de 42 millones de dólares, más intereses.

Cabe señalar que, en forma aparte, el sancionado Marcelo Brito León dedujo requerimiento de inaplicabilidad de algunas disposiciones del decreto ley No 3.538, de 1980, que crea la Superintendencia de Valores y Seguros, del D.L. No 1.263, de 1975 y del D.F.L. No 1, de 1994, del Ministerio de Hacienda, estando pendiente una demanda de nulidad de derecho público de la sanción a que fue condenado, requerimiento que en definitiva fue rechazado por el Tribunal Constitucional por sentencia de 10 de enero de 2012.

La sentencia que nos ocupa esta vez, como se verá a continuación, es de sumo interés no tanto por la suma de dinero involucrada como por el razonamiento que lleva a la Corte Suprema a resolver que la obligación del pago de una multa administrativa no se extingue con la muerte del multado, pudiendo el órgano acreedor, por lo tanto, demandar su pago a los herederos. El acuerdo contó con los votos a favor de los ministros Pedro Pierry, María Eugenia Sandoval y Gloria Ana Chevesich, y con la disidencia de los ministros Rubén Ballesteros y Héctor Carreño, quienes consideraron que se debió aplicar la prescripción de la multa por la muerte, aplicando los principios del Derecho Penal al Derecho Administrativo.

El razonamiento de la Corte puede resumirse en las siguientes frases, contenidas en los considerandos duodécimo y décimo tercero:

"Duodécimo: Que de esta manera el acto administrativo que aplicó la multa al Sr. Mackenna produjo sus efectos de manera inmediata, esto es, en el acto de su notificación aquél pasó a ser deudor de la multa y tal obligación se incorporó a su patrimonio, de lo que se sigue que el cumplimiento de la obligación allí contenida 
podía -y aún puede- serle exigido a contar del día de su notificación, a menos que la ley disponga la suspensión de la exigibilidad de aquella (...)”.

"Decimotercero: Que, en consecuencia, resulta claro que los efectos del acto administrativo que impuso la multa al Sr. Mackenna se radicaron en su patrimonio al momento en que fue notificado de la misma, de modo que la cuestión jurídica de autos no pasa por estimar que la multa se extinguió con la muerte de aquel y que, en caso contrario, implicaría desconocer el carácter personalísimo de las penas y la intransmisibilidad de las mismas, sino que reside exclusivamente en un problema de mero endeudamiento, esto es, se traduce en una discusión en torno a la existencia y vigencia del crédito cuyo pago reclama el actor (...)".

\section{LA DISCUSIÓN SOBRE LAS GARANTÍ́AS PENALES Y LAS SANCIONES} ADMINISTRATIVAS EN LA DOCTRINA Y JURISPRUDENCIA CHILENAS

En el contexto de la evolución que previamente a los años 1990 vivió el Derecho Administrativo chileno, que buscó reforzar fuertemente el control de la Administración del Estado -en áreas como la responsabilidad patrimonial del Estado o la aplicación de sanciones administrativas- se crearon e importaron diversas explicaciones y fórmulas jurídicas para controlar lo que hasta entonces no estaba controlado, o lo estaba débilmente. Así, aparecieron o reverdecieron las tesis de las nulidades imprescriptibles (doctrina elaborada por Bernaschina en los años 50 y reutilizada como doctrina-trinchera frente a decisiones ablativas o títulos de intervención de la Administración empleadas por el Gobierno de la Unidad Popular en el periodo 1970-1973), las responsabilidades patrimoniales objetivas del Estado, la imposibilidad o antijuridicidad de la invalidación administrativa o, lo que nos importa ahora, la aplicación de garantías penales a las sanciones administrativas. Se trata de tesis que carecen de aparatos teóricos sofisticados, se inclinan por posturas ideológicas anti-estatalistas, y cuyas justificaciones son también básicas de raíz iusnaturalista, como por ejemplo, la simple invocación de la dignidad humana, de la primacía de la persona o del Estado de Derecho.

Ahora bien, pasado el tiempo la aplicación de estas ideas ha mostrado su precariedad: así, las demandas de nulidad de actos administrativos dictados hace 30 años muestran las complicaciones prácticas que ofrece la idea de la imprescriptibilidad e insanabilidad, complicaciones que han sido salvadas por la jurisprudencia de la Corte Suprema de manera algo artificiosa, acogiendo la tesis de la imprescriptibilidad de la nulidad del acto, pero acogiendo también la prescripción de las consecuencias patrimoniales de esa nulidad -que, a fin de cuentas, son las 
que suelen importarle a los actores en juicio. Así también, la jurisprudencia no se demoró en notar los problemas de importar sin más desde el Derecho español la objetivación más radical posible de la responsabilidad patrimonial del Estado, consolidándose la falta de servicio como factor de imputación de la responsabilidad fiscal.

En ese contexto, como destacó ya el profesor Letelier Wartenberg, la sentencia en comento bien puede convertirse en el leading case en materia de sanciones administrativas, tal como es Aedo con Fisco en materia de prescriptibilidad de las acciones patrimoniales derivadas de la nulidad de derecho público o Seguel con Fisco en la aplicación de la falta de servicio como factor de imputación de la responsabilidad patrimonial de la Administración ${ }^{3}$.

Pues bien, cierta doctrina y la jurisprudencia tradicional sostienen que las sanciones penales y las administrativas derivan "ontológicamente" del mismo ius puniendi del Estado (como si fuere un argumento metafísico e indestructible), razón que justifica que imperen las mismas garantías para los ciudadanos en la aplicación de ambos tipos de sanciones. Por ejemplo, el Tribunal Constitucional así lo había señalado en su sentencia rol No 244, de 1996, cuestión que luego matizó en las sentencias roles No 479 y No 480.

Tal doctrina no atina a diferenciar entre un procedimiento administrativo garantista y un procedimiento administrativo sometido a garantías constitucionales específicas para potestades públicas distintas a las administrativas. En efecto, un procedimiento administrativo garantista lo es en la medida que el legislador de "bases" (artículo 63 No 18 de la Constitución) está vinculado a derechos y garantías constitucionales, pudiendo mejorar los estándares iusfundamentales (v.gr. inciso $2^{\circ}$ del artículo 18 de la ley $\left.\mathrm{N}^{\circ} 18.575\right)$. Ello se contrapone con la pretensión de aplicar en bloque la garantía del debido proceso legal propia de la potestad jurisdiccional y de la investigación penal, y las garantías penales de legalidad y tipicidad (artículo 19 No 3 de la Constitución) a la potestad administrativa; todo a partir de una homologación "metafísica".

\section{El estado actual de la JURISPRUdenCia CONSTitucional}

Hace algún tiempo atrás destacamos, a propósito de un tema mayor, cuál es la jurisprudencia constitucional chilena sobre el Derecho Administrativo San-

3 Letelier (2014), p. 1. 
cionador y, en particular, sobre las garantías que respecto a éste favorecen a los ciudadanos ${ }^{4}$. Con el solo fin de contextualizar la importancia de la sentencia de la Corte Suprema aquí comentada, volveremos a apuntar brevemente cuáles son sus tópicos.

\section{a) Derecho a un procedimiento previo, racional y justo}

En su sentencia rol No 808, el Tribunal Constitucional declaró inaplicable el art. $1^{\circ}$ de la ley No 19.989, que faculta a la Tesorería General de la República "para retener de la devolución anual de impuestos a la renta que correspondiere a los deudores del crédito solidario universitario, los montos de dicho crédito que se encontraren impagos según lo informado por la entidad acreedora, en la forma que establezca el reglamento, e imputar dicho monto al pago de la mencionada deuda”. En concreto, el Tribunal sostuvo que la norma infringía la exigencia de un procedimiento racional y justo propia del debido proceso, al poner en situación de indefensión e inferioridad al supuesto deudor, pues la Tesorería puede retener la devolución anual de impuestos "con la sola información que le proporciona el Administrador del Fondo Solidario de Crédito Universitario respectivo, sin dar oportunidad al aparente deudor a presentar otro descargo que no sea el certificado de pago emitido por dicho Administrador", pues ello "no satisface, indudablemente, las exigencias mínimas de un racional y justo procedimiento, porque no permite a quien aparece como deudor de acuerdo con la información proporcionada por el Administrador del Fondo Solidario de Crédito Universitario, ejercitar ni ante la Tesorería ni ante un tribunal de justicia otro medio de defensa que no sea la prueba del pago de la obligación y siempre que conste en un certificado emitido por el mismo ente cuya información es título suficiente para retener fondos de la devolución anual de impuestos”.

Por otra parte, el Tribunal ha entendido que el denominado principio solve et repete implica una infracción al derecho de acceso a la justicia, parte integrante del derecho a la igual protección de la ley (SSTC roles $\mathrm{No}^{\circ}$. 792, 1061, 1046, $1253,1262,1279,1345$, a propósito del art. 171 del Código Tributario; y roles $\mathrm{No}_{\text {s. }}$ 946, 968, 1332, 1356, 1382, 1391, 1418, 1470 y 1580, respecto del art. 470 del Código del Trabajo).

4 MartíneZ y ZúNiga (2011). 


\section{b) Debido proceso y constitucionalidad de la potestad sancionadora de la Administración}

Como ya hemos señalado, la doctrina administrativista más tradicional, liderada por Eduardo Soto Kloss, sostuvo en un primer momento de vigencia de la Constitución de 1980 la inconstitucionalidad de las sanciones administrativas. En tal sentido, el Tribunal Constitucional ha señalado que, "típicamente la actividad sancionadora del Estado (...) opera a través de una diversidad de normas que cumplen funciones diversas". Más concretamente, el Tribunal entiende que la potestad sancionadora es fijada en al menos tres clases de normas. En primer lugar, las que establecen las conductas debidas para los administrados. En el derecho administrativo no se vinculan en una misma norma, como típicamente ocurre en el derecho penal, la descripción de una conducta antijurídica con su correspondiente sanción, sino que se describen deberes u obligaciones de los administrados. En segundo lugar, las que entregan potestades sancionatorias a la Administración y establecen, de un modo más o menos general, que el incumplimiento a los deberes contenidos en otras normas debe ser sancionado. $\mathrm{Y}$ en tercer lugar, "las que establecen las sanciones que han de aplicarse a las conductas que infringen deberes"5. El Tribunal agregó que: "el derecho administrativo sancionador establece, típicamente en otros preceptos, los órganos que pueden juzgar las conductas que infringen deberes y los procedimientos a que debe someterse esta actividad sancionadora"6. Así, el Tribunal Constitucional expresamente ha señalado que la potestad sancionadora de la Administración no es inconstitucional.

\section{c) Potestad sancionadora de la Administración $y$ principio de legalidad}

No obstante lo anterior, el Tribunal ha venido sosteniendo de manera regular la idea de que las sanciones administrativas y las penales, "pertenecen a una misma actividad sancionadora del Estado -el llamado ius puniendi- y están, con matices, sujetas al estatuto constitucional establecido en el numeral $3^{\circ}$ del artículo $19^{7}$. Pero además, el Tribunal ha declarado que la potestad sancionado-

\footnotetext{
5 STC No 480, considerando $3^{\circ}$.

6 Ídem.

7 NAVARro (2009), p. 1132.
} 
ra de la Administración está sujeta, "al principio de legalidad; desde luego, en virtud de los preceptos básicos contenidos en el Capítulo I de la Constitución, particularmente en sus artículos $6^{\circ}$ y $7^{\circ}$ que establecen la sujeción de toda actividad de los órganos del Estado al ordenamiento jurídico (...). Complementa este principio básico de exigencia de legalidad de los actos de la administración el precepto contenido en el numeral 18 del artículo 63, en cuanto exige que sean de jerarquía legal las normas que fijen las bases de los procedimientos que rigen los actos de la administración pública y el inciso cuarto del artículo 65 en cuanto reserva al Presidente de la República la iniciativa exclusiva de las leyes que crean nuevos servicios públicos" (STC No 480, considerando $4^{\circ}$ y STC No 479 , considerando $6^{\circ}$ ).

Pero además, el Tribunal ha entendido que el principio de legalidad en materia penal también resulta aplicable a la potestad sancionadora de la Administración, en virtud de dos razones:

i) Porque la potestad sancionadora de la Administración sería parte del ius puniendi del Estado. El Tribunal ha sostenido que: "los principios inspiradores del orden penal contemplados en la Constitución Política de la República han de aplicarse, por regla general, al derecho administrativo sancionador, puesto que ambos son manifestaciones del ius puniendi propio del Estado" (sentencia rol No 244, considerando $9^{\circ}$; sentencia Rol № 479, considerando $8^{\circ}$ ). Y más concretamente, ha señalado que de entre aquellos principios resultan especialmente aplicables, "los principios de legalidad y de tipicidad, los cuales no se identifican, sino que el segundo tiene un contenido propio como modo de realización del primero. La legalidad se cumple con la previsión de los delitos e infracciones y de las sanciones en la ley, pero la tipicidad requiere de algo más, que es la precisa definición de la conducta que la ley considera reprochable, garantizándose así el principio constitucional de seguridad jurídica y haciendo realidad, junto a la exigencia de una ley previa, la de una ley cierta” (sentencia Rol No 244, considerando $10^{\circ}$ ).

ii) Porque la potestad sancionadora de la Administración supone una limitación al derecho a desarrollar actividades económicas. Al respecto, el Tribunal ha señalado que, "la aplicación del principio de legalidad a la actividad sancionadora del Estado viene también exigida por lo dispuesto en el artículo 19 No 21, en relación al 19 No 26 y al 63 No 2 de la Carta Fundamental. Para llegar a esta conclusión basta aceptar la premisa de que las normas que establecen deberes y vinculan sanciones a su incumplimiento, como las descritas en las letras a) y b) del considerando tercero que antecede, limitan el ejercicio del derecho a desarrollar una actividad económica lícita" (STC No 480, considerando 8º). Pero 
"las normas que regulen el ejercicio de una actividad económica lícita deben estar contenidos en preceptos de rango legal, según lo dispone expresamente el numeral 21 del artículo 19, al establecer que 'el derecho a desarrollar cualquier actividad económica que no sea contraria a la moral, al orden público o a la seguridad nacional', debe hacerse 'respetando las normas legales que la regulen'. En consecuencia, la Constitución reserva a la ley la regulación de la actividad económica lícita" (STC No 480, considerando 9; y en un sentido similar, STC No 479, considerandos $11^{\circ}$ y $13^{\circ}$ ).

\section{d) Potestad sancionadora de la Administración $y$ principio de tipicidad}

Consistente con la argumentación anterior, el Tribunal ha señalado también que respecto de la potestad sancionadora de la Administración el principio de legalidad incluye también el principio de tipicidad. En otros términos, corresponde al legislador determinar de manera expresa la conducta a sancionar por la Administración. Y así por ejemplo, ha declarado que: "las normas que establecen deberes a las empresas de generación o distribución eléctrica, deben estar contenidas en preceptos legales. Igual estatuto ha de aplicarse al resto de las normas que, inseparablemente vinculadas con ellas, establecen que el incumplimiento de tales deberes debe ser sancionado y las que establecen las sanciones. Es el caso de todas y cada una de las normas impugnadas de inconstitucionalidad en esta causa" (STC No 480, considerando $12^{\circ}$ ).

Pero junto a lo anterior y al igual que lo que el propio Tribunal ha sostenido respecto de la tipicidad penal, "el estatuto jurídico de la actividad sancionadora de la administración admite la colaboración de la potestad reglamentaria" (ídem). Ello porque ha entendido que, "afirmar que una determinada materia está regida por el principio de legalidad no equivale necesariamente a excluir que la potestad reglamentaria de ejecución pueda, dentro de los márgenes constitucionales, normar esa misma materia”, incluyéndose la posibilidad de que, vía potestad reglamentaria de ejecución o desarrollo, se complementen las conductas y sanciones fijadas por el legislador en el ámbito del Derecho Administrativo sancionador (ibíd., considerando 13\%). En tal sentido, el legislador debe fijar las bases esenciales, por lo que "queda entregada, salvo disposición expresa en contrario del propio Texto Fundamental, a la potestad reglamentaria del Presidente de la República la dictación de los 'reglamentos, decretos e instrucciones que crea convenientes para la ejecución de las leyes', reafirman la voluntad de la Constitución de que la ley mantenga el carácter general y abstracto, lo dispuesto en los numerales 4, 16 
y 18 del mismo artículo 63" (STC No 480, considerando 13ㅇ, y STC No 479, considerando $14^{\circ}$ ).

\section{El giro de la Corte Suprema}

En este punto, resulta útil recordar las elocuentes palabras del profesor de derecho administrativo C. Román Cordero, cuando nos dice:

"El Derecho Administrativo Sancionador es, en nuestra opinión, Derecho Administrativo Sancionador. No Derecho Penal. Se trata, en consecuencia, de una rama autónoma del Derecho Público y específicamente del Derecho Administrativo, que no sólo tiene por finalidad dotar de garantías al perseguido, como el Derecho Penal, sino que también, en tanto Administrativo, proteger el interés general y colectivo"8.

Precisamente, lo novedoso de la sentencia que ahora nos ocupa radica en que la Corte, si bien anota la existencia de una omisión del legislador en regular debidamente las sanciones administrativas, luego señala que el supuesto origen común de ambos tipos de sanciones no autorizan al juez a aplicar automáticamente las normas y principios propios del Derecho Penal al Derecho Administrativo Sancionador; tal aplicación, luego, debe efectuarse dentro de los márgenes del procedimiento administrativo sancionador, "sin perder de vista el contexto que tuvo en vista el legislador para optar por una u otra sanción" y todo ello "para garantizar, de un modo más eficaz, los intereses sociales que en dichos ámbitos se encuentran en juego". En las palabras del propio considerando noveno de la sentencia:

"Noveno: Que así, para resolver adecuadamente el asunto como ha quedado planteado, conviene dejar en claro que la decisión a través de la cual se manifiesta la potestad sancionatoria de la Administración es, no cabe duda, un acto administrativo.

Por otra parte, como bien es sabido, nuestro país carece de una normativa general sobre el ámbito sancionatorio administrativo, respondiendo la legislación, más bien, a un carácter sectorial.

Además, existe cierto consenso jurídico en cuanto a que la sanción penal y la sanción administrativa constituyen manifestaciones del ejercicio de un único poder estatal sancionatorio, el denominado ius puniendi estatal.

Sin embargo, dicha carencia legislativa y el común origen de ambas sanciones no autorizan para aplicar de manera automática las normas y principios propios del

8 ROMÁN (2008), p. 137. 
derecho penal al derecho administrativo sancionador, sino que tal aplicación debe efectuarse dentro de los márgenes del procedimiento administrativo en general y del sancionatorio en particular, sin perder de vista el contexto que tuvo en vista el legislador para optar por una u otra sanción, tal como lo reconoce el propio Tribunal Constitucional: "Aun cuando las sanciones administrativas y las penas difieren en algunos aspectos, ambas pertenecen a una misma actividad sancionatoria del Estado -el llamado ius puniendi- y están, con matices, sujetas al estatuto constitucional establecido en el numeral tercero del artículo 19" (Sentencia Tribunal Constitucional rol No 480, de 27 de julio de 2006) (...)" (el texto cursivo es nuestro).

La "mirada al contexto" que reclama la Corte Suprema da un giro a la forma en que actuaba la jurisprudencia previamente. En efecto, el problema de las garantías a los ciudadanos frente al ejercicio por la Administración de su potestad sancionatoria ya no se resolvería con la invocación ligera a principios generales, sino que "debe tener en cuenta aquellos aspectos del derecho administrativo sancionador que le confieren a esta rama una fisonomía propia y que justifican su regulación autónoma en relación con el derecho penal”. En otras palabras, de la simplicidad de la invocación, sin más, de los principios, ahora habrá que razonar de forma más compleja, preguntándose en cada caso: “QQué explica la diversidad sancionatoria? ¿Qué justifica que el legislador opte a veces por un tipo de sanción y otras, por otra? ¿Cuál es la lógica de las sanciones administrativas en los diversos campos del derecho?" 9 . El mismo considerando noveno explica la cuestión:

"En efecto, no son pocos los casos y los ámbitos en los que el legislador recurre a la potestad sancionadora de la Administración para garantizar, de un modo más eficaz, los intereses sociales que en dichos ámbitos se encuentran en juego, lo que en caso alguno implica afirmar que, por ello, la Administración queda libre del control jurisdiccional en su obrar material y jurídico.

Por tanto, el recurso a los principios del derecho penal no debe llevar a la desnaturalización de la potestad administrativa sancionatoria, de tal manera que con ello se desconozca la intención y fines que el legislador tuvo en consideración al momento de recurrir a ella para dotar de eficacia a las instituciones jurídicas que establece con ocasión de la regulación de las distintas materias" (el texto cursivo es nuestro).

9 Letelier (2014), p. 2. 
Lo anterior se justifica plenamente pues, con claridad, aun si se sostiene el mismo origen en el ius puniendi de las sanciones penales y administrativas, se está ante figuras jurídicas distintas. Ello lleva a la Corte a sostener que:

"De ahí que resulte inoficioso continuar con la tramitación de un proceso penal si se ha producido la muerte del imputado, pues su objeto es -precisamente- establecer su responsabilidad, lo que reconoce expresamente el artículo 93 del Código Penal, al disponer que dicha responsabilidad se extingue por el fallecimiento de aquél; en cambio, el objeto del proceso contencioso administrativo es determinar si la actuación de la Administración se encuentra ajustada a la legalidad, lo que implica analizar no solo el cumplimiento de la mera ritualidad que imponen las normas de tramitación del respectivo procedimiento administrativo, sino la plena vigencia de las garantías que se derivan del numeral tercero del artículo 19 de la Constitución Política del Estado.

En otras palabras, de la identidad ontológica entre la sanción penal y administrativa no se sigue la correlativa identidad de régimen jurídico, pues ello implicaría aceptar todas las consecuencias jurídicas del primero en el segundo (NiETo, Alejandro, Derecho Administrativo sancionador, Cuarta edición, Madrid, Tecnos, 2005, pp. 161 y ss.), lo que llevaría a desconocer las normas y principios de este último, como forma de lograr una artificial armonía que de dicha identidad se derivaría”.

Con todo, hay que reconocer que la idea de que el supuesto origen común de las penas penales y de las sanciones administrativas no autoriza para aplicar automáticamente las normas y principios penales no es totalmente novedosa. Así, por ejemplo, el Tribunal Constitucional en sus sentencias roles No 479 y No 480, ambas de 2006, ya razona que tales principios deben ser matizados en su aplicación administrativa. En este sentido, la misma sentencia que ahora comentamos recuerda otro fallo de la misma Corte Suprema, en los siguientes términos:

"El matiz que se debe efectuar en la aplicación de los principios del derecho penal a la sanción administrativa -y al que se aludió anteriormente- y que, en definitiva, deriva en una diferenciación entre ambos tipos de sanciones, también ha sido destacado por esta Corte, en sentencia de 25 de abril de 2010 dictada en autos rol No 2968 2010, a propósito de la extrapolación de exigencia de tipicidad que rige para la descripción de los ilícitos penales a los ilícitos administrativos, a saber: 'la naturaleza de las contravenciones administrativas, en las que confluyen componentes técnicos, dinámicos y sujetos a variabilidad en el tiempo, hace imposible su síntesis descriptiva en un precepto general como lo es una ley, de modo que el principio de tipicidad al traspasarse al ámbito sancionatorio de la Administración admite ciertos grados de 
atenuación... (Así) debe entenderse que la predeterminación de los comportamientos que configuran infracciones administrativas se satisface con la exigencia que en la ley se describa el núcleo esencial de las conductas censurables, pudiendo éstas precisarse y complementarse en aspectos no sustanciales por normas emanadas de una autoridad distinta a la legislativa, como es el Ejecutivo, por vía de decretos y reglamentos, en ejercicio de la potestad reglamentaria de ejecución que le compete'. En otras palabras, ello no quiere decir que la exigencia de legalidad (en cuanto tipicidad) no rige en materia de ilícitos administrativos, sino que en este último ámbito se permite una mayor amplitud en la configuración normativa de las conductas infractoras, lo que se explica y justifica por los diferentes aspectos y fines que determinaron la elección que hizo el legislador al optar por sancionar administrativamente y no penalmente un determinado comportamiento".

Así, lo particularmente interesante es cómo la Corte Suprema deja por un momento de lado la invocación de los principios básicos del ius puniendi-básicamente el de la responsabilidad personal- para abordar el problema de las sanciones administrativas desde la perspectiva de la teoría del acto administrativo, así como desde el análisis del procedimiento administrativo. Por ello, hay que destacar también cómo la sentencia anota un punto de radical importancia: la decisión a través de la cual se manifiesta la potestad sancionatoria de la Administración es un acto administrativo. Luego, conforme a la idea de ejecutoriedad de los actos administrativos, sus efectos jurídicos nacen de inmediato, sin necesidad de recurrir a otra autoridad, de forma que si a través del acto se imponen obligaciones, éstas nacen con dicho acto y no en una etapa posterior. Por ello, no es relevante que hubiesen estado pendientes recursos jurisdiccionales contra el acto administrativo que sancionó a don Luis Fernando Mackenna al momento en que él murió. Como señala la sentencia certeramente en la parte final de su considerando undécimo:

"En consecuencia, todos los actos administrativos -incluidos los sancionatorios, por cierto- producen sus efectos de manera inmediata, sus consecuencias jurídicas y materiales se radican en el patrimonio del administrado desde el momento mismo de su notificación, y, una vez notificado, la Administración puede exigir su cumplimiento, incluso antes de que la persona sancionada reclame de la legalidad del acto, salvo que la ley o el juez suspendan dicha exigibilidad -es decir, su eficacia, en términos de ejecutividad-, pero tal suspensión no dice relación con que los efectos del acto no se producen -esto es, no afecta su ejecutoriedad-, sino que, por el contrario, ellos se encuentran plenamente incorporados en el patrimonio del deudor desde su notificación y permanecen en tanto el juez que conozca de la reclamación no declare la ilegalidad del acto respectivo". 
Antes, adelantando esta conclusión, la Corte señala en su fallo:

"Así también se manifiesta en el establecimiento o determinación de la responsabilidad por la infracción de un ilícito penal y uno administrativo, pues existe una diferencia fundamental entre la responsabilidad penal y la administrativa, la que radica en que la primera se hace efectiva con la sentencia condenatoria ejecutoriada dictada por un órgano jurisdiccional, lo que constituye la máxima manifestación de la presunción de inocencia y también del carácter de ultima ratio del derecho penal; en cambio, la segunda se materializa con el acto administrativo dictado por aquel órgano administrativo al que el ordenamiento jurídico reconoce y autoriza para ejercer un poder punitivo y coercitivo de modo directo, como un instrumento concreto y eficaz para la satisfacción del interés general y la protección de ciertos bienes jurídicos que en determinados casos deben prevalecer sobre intereses particulares o privados, lo que en ningún caso es óbice para el control que de su ejercicio puedan hacer los tribunales de justicia, según ya se indicó”.

Esta conclusión puede parecer hasta obvia si se considera el desarrollo actual de la doctrina y la jurisprudencia iusadministrativa; pero no por ello debe olvidarse que encuentra su fundamento en la lógica del control mutuo que existe entre las funciones-poderes del Estado: el acto administrativo, en cuanto acto de la Administración Pública, no es una decisión de primera instancia como lo sería una sentencia judicial apelable; por ello, el control judicial de los actos administrativos es el control de un acto que ya existe en el sistema jurídico, que goza de una presunción de juridicidad, sin que espere ser visado por los tribunales para ser válido y eficaz.

\section{CONCLUSIONES}

Se nota un retorno al Derecho Administrativo luego de un largo vagar entre los principios del Derecho Penal buscando garantías para las personas frente al ejercicio de la potestad sancionatoria de la Administración, o lo que es más peligroso tras un largo vagar por el derecho natural o la apelación al "derecho común" o simplemente a la "historia" de las instituciones. Nosotros estamos entre quienes valoramos este retorno a la especificidad del Derecho Administrativo: la búsqueda entre aquellos principios pronto se mostró poco práctica, forzada, irreal y profundamente ideológica, lo que obligó a matizarlos, deformarlos en su aplicación a las sanciones administrativas. Pensamos que, mediando el desarrollo futuro por el legislador, la doctrina y la jurisprudencia acerca de las reglas que complementen nuestra actual rama sancionatoria del Derecho Administrativo, 
podemos resolver mejor esta clase de conflictos, con un análisis más profundo, funcional y complejo.

Con todo, puede resultar preocupante que tras este giro jurisprudencial no se desarrollen a la velocidad necesaria los criterios que vengan a reemplazar aquellos que estaban asentados por la jurisprudencia y la doctrina chilenas; en otras palabras, aunque con conocidos defectos, tales criterios buscaron dotar de garantías mínimas a los ciudadanos frente al ejercicio de la potestad sancionatoria de la Administración. Ellos se explicaron dado lo reacia que fue la doctrina nacional más tradicional a aceptar siquiera la constitucionalidad de las potestades sancionatorias administrativas ${ }^{10}$; cuando dicha discusión fue superada por el avance (necesario, por lo demás) del derecho positivo, el esfuerzo de esa misma doctrina se enfocó en dotar a las sanciones administrativas de garantías que no se encontraban explicitadas en la legislación: así, se pasó desde la aplicación rígida de los principios penales a su constante matización. Dicha evolución se nota si se comparan las sentencias No 244, de 1996, con las No 479 y No 480, ambas de 2006, del Tribunal Constitucional, evolución que destacamos en su oportunidad comentando estas últimas dos sentencias ${ }^{11}$.

Por lo anterior, resulta evidente que el "retorno" al Derecho Administrativo no puede significar la renuncia a toda garantía. En otras palabras, como bien nos dice el profesor Román Cordero:

"Por ello es evidente que el ejercicio de tales potestades debe sujetarse a principios. ¿A cuáles? Nada más ni nada menos que a los principios del Derecho Administrativo Sancionador (...). Pero como los principios del Derecho Sancionador no tienen aún una consistencia dogmática precisa, es menester, como medida de urgencia, atendido el paralelismo mas no subordinación entre esta rama y el Derecho Penal (...) 'tomar prestados' sus principios, que sí cuentan con esa consistencia, y aplicarlos -como pauta-al Derecho Administrativo Sancionador; aunque claro está de forma matizada, atendidas las particularidades de esta rama del Derecho, y si ello no es posible por la intensidad de éstas, bien puede al no existir norma expresa que señale lo contrario -como sucede en otros ordenamientos jurídicos- desviarse del esquema penal"12.

Así las cosas, resulta indudable que esta sentencia, tomando el rumbo correcto, importa un desafío mayor para nuestra doctrina iusadministrativa, que

10 Vid. Aróstica (1987); Aróstica (1991); Soto (2005).

11 ZúNiga y Cazor (2007).

12 Román (2008), p. 138. 
deberá establecer los fundamentos teóricos para, sin sacrificar la certeza ni los derechos de los administrados, permita también cumplir los intereses y necesidades colectivas que justifican la existencia de las sanciones administrativas. La autonomía del Derecho Administrativo Sancionador en nuestro ordenamiento aun es incipiente; el desafío entonces, es desarrollar ese Derecho Sancionatorio equilibrado entre el interés colectivo y los derechos fundamentales de los administrados.

Más allá de las cuestiones de lógica jurídica planteadas anteriormente, cabe destacar también que la sentencia -como suele ser con todas las sentenciastambién se ocupa de una cuestión de justicia material. En efecto, como se indicó en la introducción de este trabajo, todos los ejecutivos involucrados en el ilícito bursátil del "caso Chispas" fueron sancionados y, siendo rechazadas las reclamaciones interpuestas por ellos contra los actos administrativos que los multaron, pagaron las respectivas multas. Como se aprecia, si un hecho totalmente ajeno a la voluntad de las partes -la muerte del señor Mackennahubiese importado la prescripción de la sanción -como consideró, por lo demás, el voto de minoría de la Corte Suprema- habría significado que sólo algunos de los patrimonios que debían soportar una merma a modo de sanción hubiesen efectivamente sufrido esa pérdida; en cambio, de la forma que razonó ahora la Suprema, el patrimonio del señor Mackenna, ahora perteneciente a sus herederos, no se verá exonerado ("injustamente") de la sanción. Reconocemos que, a primera vista, este juicio pueda parecer duro: pero no hay que olvidar que, finalmente, las sanciones administrativas en esta materia en particular sirven de señales a los mercados bursátiles; la sentencia, así, es una señal contundente a esos mercados.

\section{BiBLIOGRAFÍA}

Aróstica Maldonado, Iván (1987): "Algunos problemas del Derecho Administrativo Penal”, en Revista de Derecho de la Universidad de Concepción (No 182), pp. 71-81.

Aróstica Maldonado, Iván (1991): "Un lustro de sanciones administrativas (1988-1992)", en Revista de Derecho Público (No 50), pp. 175-195.

Bermúdez Soto, Jorge (2010): Derecho Administrativo General (Santiago, Abeledo Perrot).

Letelier Wartenberg, Raúl (2014). “Garantías penales y sanciones administrativas: A propósito de la sentencia de la Corte Suprema en el llamado caso 
Mackenna" [fecha de consulta: 5 de mayo de 2015] [Disponible en: http:// www.diarioconstitucional.cl/imprimir/articulo/375/].

Martínez Estay, Ignacio y Zúniga Urbina, Francisco (2011): "El principio de razonabilidad en la jurisprudencia del Tribunal Constitucional”, en Estudios Constitucionales (Año 9, No 1), pp. 199-226.

Navarro Beltrán, Enrique (2009): "Criterios señalados por el Tribunal Constitucional en el ámbito de lo contencioso administrativo", en: Arancibia Mattar, Jaime y Martínez Estay, José (coords.), La primacía de la persona: estudios en homenaje al profesor Eduardo Soto Kloss (Santiago, Legal Publishing), pp. 1129-1137.

Román Cordero, Cristián (2008): "Derecho Administrativo Sancionador: ¡ser o no ser? He ahí el dilema”, en: Pantoja Bauzá, Rolando (coord.), Derecho Administrativo. 120 años de cátedra (Santiago, Editorial Jurídica de Chile), pp. 107-141.

Soто Kloss, Eduardo (2005): "Sanciones administrativas, ¿camino a servidumbre?”, en Gaceta Jurídica (No 296), pp. 76-88.

Zúñiga Urbina, Francisco y Cazor Aliste, Kamel (2007): "Sobre el principio de legalidad y derecho administrativo sancionador (SS.T.C. Roles $\mathrm{No}^{\circ} .479$ y 480, de 2006)", en Gaceta Jurídica (No 320), pp. 93-156. 